\title{
How Our Hands Shape Our Minds: Six Developmental Pathways
}

\author{
Gustaf Gredebäck $^{\mathrm{a}}$, Janna M. Gottwald ${ }^{\mathrm{a}}$, Moritz M. Daum ${ }^{\mathrm{b}}$ \\ auppsala University, Uppsala, Sweden

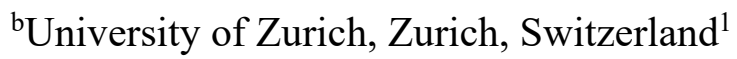

Working paper. Please do not quote or cite without the authors' permission

\begin{abstract}
Author Note
All authors contributed equally to the manuscript. Correspondence can be addressed to either of the authors: Gustaf Gredebäck, Department of Psychology, Uppsala University, Box 1225, 75142 Uppsala, Sweden, E-Mail: gustaf.gredeback@psyk.uu.se; Janna M. Gottwald, Department of Psychology, Uppsala University, Box 1225, 75142 Uppsala, Sweden, E-Mail: janna.gottwald@psyk.uu.se; Moritz M. Daum, Department of Psychology and Jacobs Center for Productive Youth Development, University of Zurich, Binzmuehlestrasse 14, Box 21, CH-8050 Zurich, Switzerland, E-Mail: moritz.daum@uzh.ch
\end{abstract}

\footnotetext{
${ }^{1}$ We want to emphasise that Sweden and Switzerland are two different European countries with the two distinct capitals Stockholm (capital of Sweden) and Bern (capital of Switzerland).
} 


\begin{abstract}
In the current, empirically grounded paper, we first explore the ways in which manual actions, that is actions performed with hands and arms such as reaching, grasping, and manipulating objects, shape the mind. Based on recent empirical research, we suggest six embodied developmental pathways which solve unique challenges faced by infants and children during development. I) Co-opted motor simulation allows action anticipation, II) interactive specialisation allows executive control to emerge from reaching and grasping. III) Active exploration and IV) error based-learning facilitate cognition and perception. Action based social interactions facilitate V) language development and VI) gesture comprehension. These pathways exemplify how manual actions and the underlying neural processes controlling actions are used by the infant to structure the world and develop cognitive capacities and learn from interactions with the physical and social world. Through an individual difference, correlational approach, we note that these abilities and processes measured in infancy have long-term associations with cognitive and perceptual development into childhood and beyond.

Keywords: development, embodied cognition, infancy, action, grasping, reaching, embodied cognitive science
\end{abstract}




\section{How Our Hands Shape Our Minds: Six Developmental Pathways}

More than 20 years ago, a theoretical paper outlined the possible benefits of walking and crawling for cognitive development, entitled "Travel broadens the mind". In this paper Campos and colleagues (2000) argued that the development of self-produced locomotion is related to a multitude of new experiences and interactions that help shape the mind. The current empirically grounded paper is inspired by this approach, exploring the many ways in which actions performed with hands and arms (reaching, grasping, and manipulating objects, henceforth referred to as "manual actions") shape the mind. Based on research from the last $\sim 20$ years, we suggest six ways in which manual actions impact the development of psychological abilities outside the motor domain. We postulate that these embodied developmental pathways help solve unique challenges faced by infants and children during development far beyond the use of the hand as a tool to manipulate the world.

The first two pathways describe neural mechanisms and processes involved in, and influenced by, the developing manual action skills: I) Motor simulation cuts down processing time and allows fast processing of social complex information, here exemplified with action anticipation, the ability to fixate the goal of other people's actions before they are achieved (Gredebäck \& Falck-Ytter, 2015). II) The interactive specialisation of brain functions allows large generic neural networks to differentiate into specialised processing systems that are involved in the solution of different tasks (M. H. Johnson, 2011). For example, we suggest that a network dedicated to planning of manual actions early in life differentiates into two specialised neural systems, one dedicated to prospective control of manual actions (motor control) and another to long-term planning (executive functions, Gottwald et al., 2016). 
The second pair of pathways describe how cognitive abilities grow through the influence of manual actions by providing novel forms and enhanced magnitudes of information. III) For example, manual exploration provides new information and increases attention to action relevant properties of objects, leading to improvements in spatial and magnitude perception (Schröder et al., 2020). IV) Hypothesis testing and error-based learning, derived from a mismatch between what we expect and what actually happens leads to a positive spiral of increasing accuracy of predictions about the world, with long-term consequences for social interactions throughout development (Gredebäck et al., 2018).

Finally, the third pair of pathways describes how we learn from social interactions through which we can transform the meaning of manual actions. This includes V) the interaction of non-verbal and verbal communication, for example via the relation between actions and action words (i.e., action-related verbs, Antognini \& Daum, 2019) and VI) the development non-verbal communication, for example via the transformation from instrumental reaching actions to referential pointing gestures.

This is not intended as a complete list of embodied pathways, nor do we suggest that manual actions are the only medium by which action shapes the mind. Instead, the current review is intended to highlight the multitude of ways in which infants take an active part in their own cognitive development - using manual actions as a prominent example to illustrate the current multidimensional embodied framework of early cognitive development.

Contrary to previously formulated theories of embodied cognition (Fuchs, 2017; Wilson \& Golonka, 2013) the current framework is not intended to replace cognition and representations with a completely non-symbolic mind. In light of current criticism of purely embodied theories, this would be limited (e.g., Caramazza et al., 2014; Lingnau \& Caramazza, 2014; Mahon, 2015a, 
2015b). Here, we argue that early in life, when language and representational skills have still great potential for further development, these processes help children structure the world and bootstrap development. Before zooming into each of the six pathways, we will start by providing a brief overview of the foundations that we, in this review, attribute so much power to - the development of reaching, grasping, and manual exploration, both from the perspective of the production of own manual actions as well as from the perspective of the perception and the processing of manual actions performed by others.

\section{The Development of Manual Actions}

When talking about manual actions, we include several components, which we will briefly define. Often, reaching and grasping are described as two components of prehension (Smeets \& Brenner, 1999). The reaching component refers to bringing the hand to the target object, the grasping component to the opening and closing of the hand around the object. Manipulation is here used as the treatment or operation of objects with the hands. These seemingly simple manual actions require the solution of a complex spatial problem. It includes the processing of the position of the reaching hand and the position of a target object. To successfully perform manual actions, a multitude of information needs to be processed and integrated into one common action representation: gaze position, target location, and limb position (Castiello \& Pierno, 2009). It is this complexity that made manual actions so attractive for researchers from different fields including motor behaviour, cognition, problem solving and their neurophysiological underpinnings, both in adults (Brass et al., 2000; Daum et al., 2007; Jeannerod, 1981; Muthukumaraswamy \& Johnson, 2004; Smeets \& Brenner, 1999) as well as in developmental populations (Beisert \& Daum, 2021; Daum \& Gredebäck, 2011; Falck-Ytter et 
al., 2006; Lockman et al., 1984; Loucks \& Sommerville, 2012; Sommerville et al., 2005; von Hofsten \& Lindhagen, 1979; von Hofsten \& Rönnqvist, 1988; Woodward, 1998).

The development of manual actions does not depend solely on the maturation of the motor cortex and the involved effectors (i.e., hands and arms) but is an active problem-solving process enabling the infant to grasp objects in their environment and to explore them by hand and mouth (Thelen et al., 1993). Reaching emerges through continuous action-perception cycles, where different developmental factors such as anatomical structure, movement preferences, and sensorimotor experiences interact in a complex manner (Williams et al., 2015). While the onset of intentional reaching, around 4 months of age (von Hofsten \& Rönnqvist, 1988), might seem to occur suddenly from an observer's perspective, quite the contrary is the case (Thelen et al., 1996). Foetuses at the $22^{\text {nd }}$ week of gestation show first manifestations of goal-directed manual movements (Zoia et al., 2007). Shortly after birth, neonates move their arms intentionally and in a goal-directed manner (Delafield-Butt et al., 2018; Delafield-Butt \& Gangopadhyay, 2013; van der Meer et al., 1995). Before the onset of intentional manual actions, infants show pre-reaching behaviour, they move their arms in the direction of visual targets (von Hofsten, 1984). These early manual actions are often jerky, have several small acceleration and deceleration phases (movement units), and vary substantially in speed and trajectories. At that time, manual actions occur more frequently when the infants look at their reaching hand and the object that they intend to reach for (von Hofsten \& Lindhagen, 1979; von Hofsten \& Rönnqvist, 1988). Through continuous exploration of their own body, its capabilities, and the surrounding environment, infants are able to select successful movement patterns within a particular context and as a consequence, manual actions emerge (Corbetta \& Thelen, 1996; Thelen \& Corbetta, 2002; Williams et al., 2015). 
At the onset of manual action production, between 4 and 6 months of age, infants touch objects, often using a rudimentary form of power grip (Butterworth et al., 1997). However, they do not yet proficiently grasp and manipulate the objects they interact with. Infants first have to overcome some interacting perceptual and motor constraints (Corbetta et al., 2000). At first, infants reactively rely on haptic information to adapt their grip after their hands have touched the object. Later, by the age of 7 to 9 months, infants predictively adjust their grip both with respect to orientation and hand aperture before making contact with a goal object and form a radial digital grasp (Newell et al., 1989; von Hofsten \& Rönnqvist, 1988). During this period of development, fundamental changes do not only occur in the development of manual actions but also in motor control more generally. Postural control is improving and constraining motor synergies (such as bimanual reaching) are disappearing (Corbetta et al., 2000). Around the age of 12 months, infants demonstrate the advanced pincer grip, allowing them to grasp even tiny objects with the tips of their thumb and index fingers (Forssberg et al., 1992).

In the process of developing manual actions, infants engage in prospective motor control (for a review, see Gottwald, 2018). Prospective motor control is an anticipatory process that allows an individual to adapt one's movements to future constraints, tasks, and environments (von Hofsten, 2004). In other words, infants control their body movements with respect to future states of the world. Examples are reaching in multiple-step actions, where infants adapt their reaching speed to future action step requirements (Gottwald et al., 2017), and reaching for moving objects, where infants direct their hands towards locations where the object will be later in time, intercepting the object along its future path (Hespos et al., 2009; von Hofsten, 1983). This behaviour does not require a built-in and predefined developmental plan or a process of active construction in which the child is seen as an active agent. In contrast, when seen from a 
dynamic systems perspective, these behaviours emerge in a process of self-organisation based on the increasingly complex interactions with perception and sensorimotor systems (Thelen, 1992). In this process, infants engage in exploration. Starting off with spontaneous movements, infants are internally motivated to explore movements, their bodies' capabilities, and the constitution of the physical world. Hence, these exploratory behaviours do not need to be reinforced or imitated to evolve but emerge as a result of the the infants' inherent curiosity in combination with the constraints and opportunities the environment provides for the infant (Adolph et al., 2012; Delafield-Butt \& Gangopadhyay, 2013).

In the process of developing manual actions, infants also learn about the world around them - perhaps this is even part of the motivation to practice and develop manual skills, similar to what have been observed for walking and crawling (Campos et al., 2000; Gibson, 1978; Hoch et al., 2019). As a consequence, manual actions, perception, and cognition develop together in a co-dependent, dynamic, and constructive manner.

To summarise, grasping and in particular reaching actions have their onset already before birth. They quickly develop from being rudimentary and uncoordinated early in the first year of life to becoming more and more fine-tuned and efficient towards the end of the first year. In the following, we use this information and describe different pathways of how emerging and finetuned manual action skills impact the development of more or less related cognitive skills.

\section{Cognitive and Neural Mechanisms That Rely on Actions to Solve Cognitive and Perceptual}

\section{Challenges}

\section{Pathway I) Action Anticipation, and the Case of Co-opted Motor Simulation}

Keeping track of other people's manual actions and the related goals is a challenging task for a young infant, and not always simple for adults either (Falck-Ytter et al., 2006; Wermelinger 
et al., 2018). Foveal vision ensures that high acuity visual information can only be obtained from a small part of the visual field (Braddick \& Atkinson, 2011), making it essential to look where important events occur to perceive, interpret, and learn from these events (Gredebäck \& FalckYtter, 2015). At the same time, saccadic reaction times are slow, particularly early in development (approximately $200 \mathrm{~ms}$ latency in adults and 400-700 ms in infants; Gredebäck et al., 2006; Kenward et al., 2017). To overcome these challenges, infants develop the ability to predict future states of manual actions by anticipating the next steps and action goals and sub goals (Gredebäck et al., 2009). Infants, with their restricted information processing capacities and lack of world knowledge, achieve this feat with the help of an embodied co-opting mechanism, where processes dedicated to own action control and future oriented planning are used to anticipate the future state of other people's actions (Gredebäck \& Falck-Ytter, 2015). More specifically, neural mechanisms that have evolved to support manual actions are used to anticipate the goal of others actions, one's own motor plans for manual actions can be used to calculate the future locations of other people's manual actions (Kilner et al., 2007). It is proposed that seeing someone else's actions unfolding in real time activates the corresponding motor plan used to execute the same action (Rizzolatti \& Fogassi, 2014). These plans include the current and future state of the entire body - both action (how to act) and perception (where to look). This information can be used to extrapolate future locations of other people's actions and allow infants (and adults) to look towards the future state of an event. This embodied process provides a foundation for the onset of manual action anticipation in infancy, as demonstrated by correlations between onset of specific manual action capacities (i.e. placing objects in the mouth, reaching for, grasping, and manipulating objects) and the anticipate of the goal of similar actions 
performed by others (Cannon et al., 2012; Daum et al., 2011; Falck-Ytter et al., 2006; Gredebäck \& Kochukhova, 2010; Melzer et al., 2012; Rosander \& von Hofsten, 2011).

A similar motor dependency still remains as one factor impacting (manual) action anticipation beyond infancy, in fact, motor cortex activity continues to impact action anticipation in adulthood, as demonstrated by TMS studies interfering with the neural control of the hand/arm and the subsequent reduction in anticipation of the goal of manual actions (Costantini et al., 2014; Elsner et al., 2013). On a neurological level this is often described as the mirror neuron system, centring on the inferior parietal lobule, the inferior frontal gyrus and the ventral premotor cortex (Gatti et al., 2017; Molenberghs et al., 2012) in adults. We suggest that this process operates throughout the life span, based on the correlational developmental literature described above and recent findings demonstrating an association between deteriorated manual proficiency and fewer predictions when observing manual actions in adults and elderly (Wermelinger et al., 2019).

\section{Pathway II) Executive Functions, and the Case of Interactive Specialisation}

\section{Executive Functions and Prospective Motor Control}

As noted above, the performance of prospective manual actions is a complex process with restricted temporal requirements. Manual actions often take only one to two seconds to unfold in infants (Domellöf et al., 2015). In addition to controlling the immediate environment through manual actions, infants are also remarkably good at planning actions that stretch over several subsequent goals (Gottwald et al., 2017). Early in life humans do not only develop the ability to reach and interact, they also develop planning skills that stretch over longer time periods, requiring executive control, including inhibition, working memory, and set shifting 
(Miyake \& Friedman, 2012). These processes develop slowly over the course of many years, however, at this time, no consensus exists on their developmental origin (Karr et al., 2018).

One theoretical proposition, in line with the general notion of embodied development, is that the early development of executive functions originates from the ability to reach and grasp, to plan one's own prospective manual actions (Gottwald et al., 2016). The suggestion that there is a causal link between the development of reaching and grasping on the one hand and executive functions on the other is based on several correlational findings. First, the microstructure of 18month-olds' reaching (velocity of the first movement unit during reaching) is related to inhibition and working memory in standard executive function tasks. This suggests a functional link between the ability to reach and grasp (planning), the ability to not reach when instructed to do so (inhibition), and the ability to keep multiple objects in mind at the same time (working memory) early in life (Gottwald et al., 2016). Second, 1-year-olds' motor proficiency (walking and standing) is related to executive control in 33-35-year-old adults, measured both behaviourally (e.g., via tests of working memory) and neurologically (increased grey-matter density in fronto-cerebellar networks, Ridler et al., 2006). Third, in adults, a neural network involving the posterior parietal cortex and the frontal cortex are involved in executive-function related cognitive activities, such as action planning and decision-making (Andersen \& Cui, 2009), coupled with strong co-activation of the dorsolateral prefrontal cortex, the cerebellum and the motor cortex (Barkley, 2012; Diamond, 2013). This suggests a network for planning that involves both motor and frontal areas. Finally, infants with more motor experience, as indicated by earlier onset of walking and crawling, also show more goal-directed reaches and less extraneous movements (D’Souza et al., 2017). 
According to this suggestion, executive functions might develop from prospective motor control. Gottwald et al (2016) suggests that the transformation from prospective control to executive functions is achieved by a process of interactive specialisation (Karmiloff-Smith, 2015). Early in infancy, the brain is plastic and undergoes rapid and extensive development and reorganisation. From a neuroconstructivist perspective (Karmiloff-Smith, 2015), the brain develops dynamically and gradually from broad networks that manage a diverse set of tasks (in this case prospective control of action) to two functionally specialised networks performing a more narrow set of tasks with a high degree of efficiency (in this case one system for prospective control of action and another, related system, for executive functions). In other words, neural differentiation and specialisation creates opportunities for new temporal horizons to develop, for executive long-term planning to emerge from the need to prospectively control one's own hand and manual actions.

Another, complementary way to view the correlations and associations between early motor performance and later executive functions is possible, by adopting a dynamic systems perspective (e.g., Smith \& Thelen, 2003). The central components of dynamic systems (DS) are self-organisation and emergence, that is, a system (like a human infant) generates novelty through their own activity. Via self-organisation, the parts of a system are coordinated without an organisational executive entity that provides explicit instructions, and that the pattern and the order of occurrence emerge from the dynamic interactions of the components of the complex system. As a consequence, prospective motor control might emerge as a consequence of the development of different aspects including the maturation of motor and the cognitive control areas of the brain, the initial somewhat random movement patterns of the arms (and the whole body), and the observed consequences and possibilities of manual actions. With increasingly 
accumulated manual action experiences, infants enhance their future-oriented action strategies. Over time the temporal planning horizon is extended in a way that allows strategic planning over days and years.

In many respects these two alternative theoretical models (interactive specialisation and dynamic systems) are complementary and operate on different levels, it is quite possible that dynamic organisation on a neural level leads to interactive specialisation on a more global neural level, both perspectives arguing for an active role of manual actions and infants' own exploration for long-term planning and executive control.

\section{Manual Actions Enrich the Mind}

\section{Pathway III) Learning Through Active Manual Exploration}

Early manual actions cause (often somewhat unplanned) effects in the environment. Piaget (1953) referred to this behaviour as circular reactions, be it in the sense of the repetition of (initially randomly) produced effects in the environment (i.e., secondary circular reaction) or the in-depth exploration of the properties of objects through novel manual actions (i.e., tertiary circular reactions). These actions are to a large extent performed with one's hands and most of these manual actions seem rather playful. They include repeated patterns of movements or sounds, such as shaking, banging, or babbling. They furthermore include social interactions such as "peekaboo" games in which a parent makes objects repeatedly disappear and reappear. At this age, children's ongoing mastery of their body in relation to manipulable objects can be characterised by "practice play". With increasing age, children gather information about object properties, about how to manipulate objects, and about the effects their actions cause in the environment. 
Play comes in many forms and is a term that is challenging to define and isolate.

Traditional accounts define play as behaviour that is voluntary and pleasurable, not dependent on external reward, that appears variable, incomplete, or modified in some manner compared to the instrumental actions that are mimicked, and that is dampened during the experience of negative feelings or emotions (Burghardt \& Pellis, 2018). Incorporating all of these dimensions in a viable operational definition of play in infancy is challenging. Manual actions are per definition variable at this age, and adding stress or negative experiences to an infant is clearly undesirable. This leaves us with the first part of the definition, that is, actions that appear to be rewarding for their own sake and motivated from within (here referred to as sensorimotor play, Bergen, 2018). Infants often try mastering how to control their arms during reaching, and while exploring objects via trial-and-error learning. This behaviour might be considered sensorimotor (manual) play according to the above definition. Infants learn about their own body and develop their action capacities through self-generated and self-motivated actions, the correlation between information from different senses, and the error signals that new and unpredictable actions give rise to (Allen \& Friston, 2018; Burr \& Jones, 2016; von Hofsten, 2004). A process with close proximity to circular reaction assumed to drive development according to Piaget (1953). We argue that it is through sensorimotor play that we develop our manual action capacities and learn about the world, that active exploration is the foundation for all of the processes described in this paper.

This process can be exemplified with the "Active Exploration Hypothesis" (Schröder et al., 2020). According to this perspective, infant's playful manual interactions with the world unlock, and heighten attention to, information that provides nourishment to the growing mind. More specifically, as infants play they experience a rich world composed of visual information 
integrated with information about object textures (Granrud et al., 1984), weights (Gottwald \& Gredebäck, 2015), forms and sizes (Clifton et al., 1991). These are all aspects required to successfully plan and execute manual actions (von Hofsten, 2004). As a consequence, infants learn about how the physical world is structured. Manual actions allow infants to improve mental capacities, including mental rotation (Frick \& Möhring, 2013; Slone et al., 2018), the ability to bind partially occluded objects to single integrated entities (S. P. Johnson, 2010), to detect causal events (Rakison \& Krogh, 2011), to process object forms (Schröder et al., 2020), and develop a better acuity of the approximate number system (Lindskog et al., Manuscript under review). Put simply, we learn about the world by actively exploring and manipulating it.

To provide a concrete example of how cognition benefits from active manual exploration we draw on the example of the approximate number system (ANS). The ANS allows infants to detect and process approximate magnitudes and relate large sets of objects to each other in terms of "more" vs. "less" (Halberda \& Feigenson, 2008). Traditionally seen as a core cognitive ability (Feigenson et al., 2004) with firm routes in behavioural ecology and comparative psychology (Brannon \& Merritt, 2011) the role of experience is seldom discussed. According to our suggestion, biology has provided the mechanisms needed to process information (such as estimated numerical magnitude information by the ANS). But it is, at the same time, up to the action system, and an infant's active interaction with the world, to add the nourishment needed for this system to develop and for its processing capacity (known as acuity in the ANS literature) to increase (e.g., allowing accurate detection that a set of 12 items is more than 10 , whereas previously only being able to distinguish a set of 12 items from a set of 6). In this context, the active exploration hypothesis should be seen as one process through which information from 
playful manual actions fuel the mind, by providing information and experiences needed during development.

In sum, playful (manual) interaction with the world broadens the mind by providing new sources of information and by increasing our attention to action-relevant properties, well beyond what passive observation can achieve. We suggest that this internal drive to explore, learn, and develop can be conceptualised as play, assuming that it develops on its own, without external reward because the effects that play results in are rewarding in itself.

One potential critique of this suggestion is that play should involve incomplete actions to separate instrumental from playful actions. From our perspective this is not a meaningful distinction early in life as all actions and interactions are underlying constant change. Manual actions are not fully developed during the first year of life and are often executed with large degrees of error and lack of precision (e.g., von Hofsten, 1983). Instead of focusing on a binary distinction between complete and incomplete actions we take a graded developmental approach. Infants' manual actions sometimes achieve their goal, other times if they fail, but there is always room for improvement and infant's manual actions are always incomplete/immature, from an adult perspective.

Admittedly, deciphering whether this is play or a different form of activity, separate from classical definitions of sensorimotor play, is challenging. Regardless of whether infants' actions and interactions with the world constitute play, or play-like behaviour, infants' active manual exploration provides valuable information that helps structure and enrich the infant's world. Manual actions serve as "food for thought"; they result in novel experiences and opportunities to learn about the world, challenging current knowledge and foster development. 


\section{Pathway IV) Error-Based Learning and Internal Models}

Imagine observing two people sitting at a table. One of the individuals interacts with a series of toys, the other person asks to get one of the objects. At this point several things can happen, the toy can be handed over in an expected (e.g., placing toys in the recipient's outstretched hand) or an unexpected (e.g., placing toys on the recipient's head) manner. In this case 4- to 12-month-old infants increase their attention more to the unexpected than to the expected event (Gredebäck \& Melinder, 2010; Juvrud et al., 2019).

This response to the violation of an expected outcome of an event is closely connected to action anticipation, both empirically (Gredebäck et al., 2018) and conceptually (Gredebäck, 2018). When looking at a location in space, in anticipation of something interesting to happen, infants generate an implicit assumption about the future state of the world (Burr \& Jones, 2016). If events do not unfold as expected, the expectation is adjusted and, for example, a corrective saccade is executed and infants increase their attention to the subsequent events. The latter is evident via an increase of pupil diameter (Gredebäck \& Melinder, 2010; Jackson \& Sirois, 2009), looking times (Brandone \& Wellman, 2009; Daum et al., 2008), or EEG components such as the N400 (Reid et al., 2009). Here, we hypothesise that these error signals require infants to update their expectations about future events and learn from their mistakes, in a manner consistent with the notion of embodied predictive coding (Allen \& Friston, 2018) and the notion of "internal models" that incorporate current states of the world, one's own actions, and the expected and real consequences of these actions, in a forward model of learning by doing (Ito, 2008; Wolpert et al., 1998).

According to this account, the foundation for this learning system early in infancy is firmly placed in their own (manual) actions and the embodied processes described above. Being 
able to act in the world requires future-oriented motor plans. In turn, these motor plans are used to calculate future steps of other people's actions. Explicit anticipations allow implicit hypothesis testing and learning through error signals derived from the mismatch between where we look and where things really occur. In essence, the development of manual actions bootstraps error-based learning early in life (Gredebäck, 2018).

Recently published data support this suggestion. Six-month-olds' manual actions (in this case, their reaching actions) correlate with their ability to predict manual actions of another person, which in turn is correlated with the increase of attention to unexpected manual social interactions (Gredebäck et al., 2018). The reactions to violations of expectations have been strongly related to learning in infants. The increase of attention caused by the unexpected outcome of an event resulted in enhanced learning (Stahl \& Feigenson, 2015). Furthermore, both action anticipation and increased attention in infancy are related to higher cognitive functioning at two years of age (assessed via inhibition and pro-social exchange).

By evaluating other people's actions and adjusting one's own expectations according to observed events, infants create a model or representation of other people's actions that goes beyond the computations of the motor system, as outlined above. This representation allows infants to sharpen their predictions about other people's actions in general (working together with embodied anticipatory abilities) and facilitate an appropriate response during more complicated social interactions later in life. This acquired knowledge of other people's actions and goals can be used in social interactions, even when these involve the instruction to not reach for an interesting object (inhibition; Marciszko et al., 2020) or when asked to help clean up a messy room (pro-social exchange; Juvrud et al., 2019). This suggests these processes provide a foundation for long-term social cognitive development. 
In sum, we propose that prediction errors early in life provide a foundation for higher cognitive development via social understanding that allow cultural transmission of knowledge and the ability to read social situations and their requirements (Marciszko et al., 2020). The heavy reliance on the motor system as a foundation of action understanding, and actions as a source for error-based learning, makes this an embodied process.

\section{Actions and Social Interactions}

\section{Pathway V) Language Development}

In addition to performing and planning their own manual actions, infants learn from others and apply their action competencies in the interactions with them. One phenomenon of parent-child interactions is that both parental and child behaviour is often accompanied by words. Parents provide labels, instruct, and comment what they and their child are doing. In the context of language development, there is evidence suggesting that actions and words should not be regarded as separate entities for young infants. In particular with respect to manual actions, language is full of expressions that are derived from manual actions. "Management" comes from the Italian "maneggiare" which means "guiding by the hand". "Digital" has its origin in the word “digit". Further examples are "to grasp an idea", "to comprehend", "to reach for the stars", etc.

Empirical evidence also shows a close relation between manual actions and language development. For example, an increase of rhythmic arm gestures is related to the beginning of rhythmic sound production such as reduplicated babbling (Thelen, 1979). Names of objects that are easy to manipulate with the hands (e.g., ball) enter the productive vocabulary repertoire first (Nelson, 1973; Rodgon et al., 1977). Even abstract terms such as addition (to add), subtraction (to remove), and zero (the absence of entities) have been suggested to develop from action and 
provide the foundation for evermore advanced forms of math via embodied mathematical metaphors (Lakoff \& Núñez, 2000).

With respect to manual actions, cross-sectional evidence suggests a bidirectional influence of verbal and nonverbal communication. On the one hand, language can influence action processing. When infants hear a word describing a manual action (e.g., "constructing") before seeing the respective action, language seems to interfere with action anticipation at 12 months but facilitates action anticipation at 24 months (Gampe \& Daum, 2014; Sciutti et al., 2016). The manual action words presented in an auditory form activate the children's motor cortex (Antognini \& Daum, 2019). Some evidence suggests that these effects are related to the infants' own language skills. For example, the anticipation of the correct referent upon hearing a sentence such as "The boy is eating the cake" is related to the child's active vocabulary (Mani et al., 2016; Mani \& Huettig, 2012). On the other hand, manual actions are beneficial for children's word learning. For example, when toddlers learn the labels of novel objects, imitating the use of these objects helps them to better learn the label (Gampe et al., 2016). Here, the linguistic information learned about the object label is enriched by additional manual action information. This is in line with the intersensory redundancy hypothesis: Information presented redundantly and in temporal synchrony across different modalities enhances attention and facilitates learning (Bahrick \& Lickliter, 2014).

Further evidence for the link between words and actions comes from research focusing on the neural basis of action and language. These studies demonstrate similar brain responses to violations in both categories, actions and words. This is the case for violations of semantic content (Friedrich \& Friederici, 2005) and manual actions as (Reid et al., 2009) as well as for violations of syntactic rules in language (Friederici, 2005) and manual action sequences 
(Maffongelli et al., 2018). Maffongelli and colleagues (2018) investigated the neural processing of structural violations of observed actions in infants. The infants were presented with sequences of familiar goal-directed actions in the correct temporal order or with two temporally adjacent steps being reversed, which resulted in the fact that the action goal could no longer be achieved. The observation of this violation resulted in bilateral frontal positivity effects in the EEG, reflecting, similar to the processing of spoken language (Friederici, 2004) a reanalysis of the processed sequences and the structural reintegration of the unexpected structure.

Together these findings suggest that action and language are not two distinct systems early in infancy, but that they rely on each other to create meaning and structure to the world. In particular manual actions for which the verbs are acquired early, and that are of high relevance for the children, there appears to be a strong relation between hearing and doing, a growth in vocabulary size driven in part by action.

\section{Pathway VI) The Embodied Foundations of Gesture Comprehensions}

In addition to language, social interactions also include a vast amount of referential manual actions such as pointing and joint attention that are precursors to linguistic abilities and later vocabulary size (Carpenter et al., 1998; Iverson \& Goldin-Meadow, 2005; Lüke et al., 2017). Early in life, even before infants start to use spoken language, infants produce a number of ries gestures such as deictic (e.g., declarative or imperative pointing), beat (e.g., rhythmic manual co-speech gestures), and iconic (Leung \& Rheingold, 1981).

Pointing is one particular gesture that we argue to have a strong embodied foundation. Pointing is one of the most important referential actions used by infants and adults across the globe (Tomasello \& Farrar, 1986). Here, we propose that referential pointing gestures have a foundation in reaching and the ability of parents to detect and/or infer goals and intention from 
infants' actions. When infants develop the ability to reach and grasp for objects, they inadvertently inform others about what they intend to do and what they aim to achieve - they make their goals (object to be reached for) explicit and available to others. Caregivers respond to infants reaching by attending to the object of desire or by aiding and delivering the object to the infant's hand. This behaviour becomes an instrumental aid for the young actor. When infants start to rely on manual actions and subsequently on pointing to communicate about objects in the external world, the loop is closed and a referential and symbolic action has emerged.

This proposal receives both empirical and theoretical support. First, different forms of pointing emerge during the first year of life, whole-hand pointing and index-finger pointing. While whole-hand pointing occurs earlier during development (Lock et al., 1990), index-finger pointing seems to be related to a better understanding of communicative intentions. Infants mostly start out by pointing with their whole hands and only later develop index-finger points (Ger et al., 2018; Kita, 2003). Infant index-finger pointing is related to communicative and social cognitive development. For example, one-year-olds who used index-finger pointing showed increased understanding of others' communicative intentions, pointed more frequently, and vocalised more often when pointing than same aged peers who pointed with the whole hand (Liszkowski \& Tomasello, 2011). This developmental trend is related to the perception of pointing gestures. Recent results showed adults to be sensitive to the direction for several hand forms (whole hand, index, pinky) with a larger cueing by the index finger than the whole hand. In contrast, 12-month-olds showed a cueing effect only for the whole hand but not for other forms of pointing (Ger et al., 2021).

Further, whole-hand reaching can be related to reaching, and as soon as infants start to reach in a proficient manner, they also demonstrate sensitivity to the goals of other people's 
reaching actions, as demonstrated by covert attention shifts from a reaching hand to the object being reached for (Gredebäck \& Daum, 2015). This close developmental correspondence between production and perception of reaching (and/or whole hand pointing) can be demonstrated through priming studies with eye tracking (Daum \& Gredebäck, 2011) and through EEG studies targeting a social goal related ERP component known as P400. More specifically, the perception-production link is demonstrated in both correlational studies mapping the development of reaching production and comprehension and active training studies where reaching is facilitated with sticky mittens training and effects are observed on the perception of reaching by others (Bakker et al., 2016).

At 8 months of life the same neural correlates emerge when observing pointing hands (Melinder et al., 2015), a P400 that is stronger to congruent than incongruent pointing. However, infants only start to point around 10 to 12 months of age (Liszkowski et al., 2004), demonstrating a clear gap between onset of action and perception. The ERP morphology and typology indexing comprehension of reaching and pointing looks highly similar (Gredebäck \& Daum, 2015) but without a clear temporal correspondence the evidence supporting this claim is admittedly weaker than some of the other claims made in the paper.

This temporal disconnect can either be used to argue for the fact that reaching and pointing are fundamentally different actions with different developmental trajectories. Another possibility, brought forward here, is that pointing emerges from reaching and develops as an adaptation to a universal cultural expression of object referral (Liszkowski et al., 2012), that is similar to reaching but adjusted based on parent-child interactions, as stated above. Recent work demonstrating that reaching at 8 months of age has a clear social and referential component, with more reaching for objects placed outside the infants reaching space when adults are present and 
available to help then when others are absent (Ramenzoni \& Liszkowski, 2016), support this notion. It is clear from this work that reaching serves a communicative role at 8 months of age, the same time when infants start to interpret other people's pointing actions as goal directed (Gredebäck et al., 2010). According to this embodied account of pointing, reaching starts off as an instrumental action that quickly gains a referential meaning by caregiver's responses. Together infants and their caregivers shape the development of social referencing, both taking an active part in the transformation from instrumental manual reaching actions to referential pointing gestures.

The studies reviewed above suggest a potential embodied foundation of pointing. At the same time, it is worth noting that we are not suggesting that all communicative gestures can be derived from action and embodied processes. For example, it is possible that imperative pointing serves the purpose of requesting something that is out of reach and might be closely related to (the unsuccessful) reaching of an object. At the same time declarative pointing serves the purpose of informing others, and might therefore be more closely related to the communicative intentions (and later language). These two different types of pointing are most likely related and interlinked over development but it is possible that there is more than one route to pointing, from action and language (an ability that in itself in many ways are grounded in actions, as listed above). Other communicative actions, such as give-me gesture (open hand with palm up), do not appear related to an infant's tendency to perform the same gesture when requesting objects (Bakker et al., 2015). Nor with the ability to understand the same gesture being produced by others (Elsner et al., 2014). Perhaps some social actions, like the give-me gesture, are simply symbolic at first and only after it is learned will infants and children rely on this action for 
communication. All processes and actions are not embodied, but action provides a foundation and scaffold for many psychological processes early in life.

\section{On the Interaction Between Innate Processes, Statistical Learning, and Embodied}

\section{Cognition}

We are not born with a clean slate but a set of basic processing mechanisms that help us make sense of relevant aspects of the world (Daum \& Prinz, 2011) such as a preference for biological motion (Simion et al., 2008), faces (M. H. Johnson et al., 1991), and eye contact (Farroni et al., 2002), to process approximate numbers (Izard et al., 2009), and to detect statistical regularities (Bulf et al., 2011). The fact that similar biases are found in other species (Regolin et al., 2000) suggests that this is not a central aspect of human cognition and development but rather a more global feature of neural systems. Though the possibility has been raised that some of these biases arise from neonatal actions and experiences (Juvrud et al., 2019; Wilkinson et al., 2014) it is unlikely that they all originate from actions and explorations. Many other animals are born with a set of abilities that allow them to relatively quickly survive in the world with little support from others. It is important to acknowledge that biology most likely has provided us with a similar toolbox of basic processes that allow new-born infants to orient to others and process information in an efficient manner.

It has, at the same time, been proposed that human cognition developed from language and the ability to create abstract concepts, associated with language development (e.g., Spelke, 2017). Functional language production is usually thought to start around 12 months (e.g., Swingley, 2009) while infants start to process phonetic information prior to this (e.g., Bergelson \& Swingley, 2012; Friederici, 2005). At the same time, infants develop a large array of skills before 6 and 12 months and a strong correlation between the development of cognition and the 
onset of language is missing from the field (that is, a sharp increase in cognitive development that cannot be explained by infants increased understanding of instructions or verbal information essential to a task).

It is in the space between the assumption of innate processing mechanisms and abstract symbol manipulation, that embodied processes are essential for bootstrapping cognition. Using the principles described above, embodied cognition can help to initiate a journey that propels human cognitive development. The unique dimension of the, here presented, embodied account is to emphasise a specific point in time when actions and interactions are crucial for human development. With basic manual action skills in place, it is possible to learn from others, to rely on symbols, and to take part in the long chain of cultural knowledge transmitted through generations. As demonstrated above, embodied processes continue to provide an impact throughout life, but are supplemented with additional processes that create a redundancy in the system. This allows cognitive capacities to remain even if our bodily capacities decline. One example from the other end of the life span are scaffolding processes that are involved in the development of complementary, alternative neural circuits to achieve a particular cognitive goal (e.g., Park \& Reuter-Lorenz, 2009).

The six pathways described above are, according to our suggestion, the unique human capacity that allows us to make use of actions are in combination with an increasingly powerful ability to process information. The plasticity of the human brain is remarkable and the re-wiring described as interactive specialisation above (Karmiloff-Smith, 2015) is far beyond what is seen in other species (Hrvoj-Mihic et al., 2013). Furthermore, humans are remarkable at the ability to integrate information in novel ways across domains and time (Ghirlanda et al., 2017). Actions and experiences are the nourishment needed to develop and overcome some difficult challenges 
that humans face early in life. By utilising information and experiences derived from (manual) actions, human infants can kick-start their cognitive journey and start to decipher the social and physical world and plan their actions and interactions. 


\section{References}

Adolph, K. E., Cole, W. G., Komati, M., Garciaguirre, J. S., Badaly, D., Lingeman, J. M., Chan, G. L. Y., \& Sotsky, R. B. (2012). How do you learn to walk? Thousands of steps and dozens of falls per day. Psychological Science, 23(11), 1387-1394. https://doi.org/10.1177/0956797612446346

Allen, M., \& Friston, K. J. (2018). From cognitivism to autopoiesis: Towards a computational framework for the embodied mind. Synthese, 195(6), 2459-2482. https://doi.org/10.1007/s11229-016-1288-5

Andersen, R. A., \& Cui, H. (2009). Intention, action planning, and decision making in parietalfrontal circuits. Neuron, 63(5), 568-583. https://doi.org/10.1016/j.neuron.2009.08.028

Antognini, K., \& Daum, M. M. (2019). Toddlers show sensorimotor activity during auditory verb processing. Neuropsychologia, 126, 82-91.

https://doi.org/10.1016/j.neuropsychologia.2017.07.022

Bahrick, L. E., \& Lickliter, R. (2014). Learning to attend selectively: The dual role of intersensory redundancy. Current Directions in Psychological Science, 23(6), 414-420. https://doi.org/10.1177/0963721414549187

Bakker, M., Kaduk, K., Elsner, C., Juvrud, J., \& Gredebäck, G. (2015). The neural basis of nonverbal communication-Enhanced processing of perceived give-me gestures in 9-monthold girls. Frontiers in Psychology, 6. https://doi.org/10.3389/fpsyg.2015.00059

Bakker, M., Sommerville, J. A., \& Gredebäck, G. (2016). Enhanced neural processing of goaldirected actions after active training in 4-month-old infants. Journal of Cognitive Neuroscience, 28(3), 472-482. https://doi.org/10.1162/jocn_a_00909

Barkley, R. A. (2012). Executive functions: What they are, how they work, and why they evolved. 
Guilford Press.

Beisert, M., \& Daum, M. M. (2021). Compatibility effects in young children's tool use: Learning and transfer. Child Development, 92(1), e76-e90. https://doi.org/10.1111/cdev.13455

Bergelson, E., \& Swingley, D. (2012). At 6-9 months, human infants know the meanings of many common nouns. Proceedings of the National Academy of Sciences, 109(9), 32533258. https://doi.org/10.1073/pnas.1113380109

Bergen, D. (2018). Infant sensorimotor play: Development of sociocultural competence and enactive cognition. In J. L. Roopnarine \& P. K. Smith (Hrsg.), The Cambridge Handbook of Play: Developmental and Disciplinary Perspectives (S. 125-141). Cambridge University Press. https://doi.org/10.1017/9781108131384.008

Braddick, O., \& Atkinson, J. (2011). Development of human visual function. Vision Research, 51(13), 1588-1609. https://doi.org/10.1016/j.visres.2011.02.018

Brandone, A. C., \& Wellman, H. M. (2009). You can't always get what you want: Infants understand failed goal-directed actions. Psychological Science, 20(1), 85-91. https://doi.org/10.1111/j.1467-9280.2008.02246.x

Brannon, E. M., \& Merritt, D. J. (2011). Evolutionary foundations of the approximate number system. In S. Dehaene \& E. M. Brannon (Hrsg.), Space, Time and Number in the Brain (S. 207-224). Academic Press. https://doi.org/10.1016/B978-0-12-385948-8.00014-1

Brass, M., Bekkering, H., Wohlschläger, A., \& Prinz, W. (2000). Compatibility between observed and executed finger movements: Comparing symbolic, spatial, and imitative cues. Brain and Cognition, 44(2), 124-143.

Bulf, H., Johnson, S. P., \& Valenza, E. (2011). Visual statistical learning in the newborn infant. Cognition, 121(1), 127-132. https://doi.org/10.1016/j.cognition.2011.06.010 
Burghardt, G. M., \& Pellis, S. M. (2018). New directions in studying the evolution of play. In J. L. Roopnarine \& P. K. Smith (Hrsg.), The Cambridge Handbook of Play: Developmental and Disciplinary Perspectives (S. 11-29). Cambridge University Press. https://doi.org/10.1017/9781108131384.002

Burr, C., \& Jones, M. (2016). The body as laboratory: Prediction-error minimization, embodiment, and representation. Philosophical Psychology, 29(4), 586-600. https://doi.org/10.1080/09515089.2015.1135238

Butterworth, G., Verweij, E., \& Hopkins, B. (1997). The development of prehension in infants: Halverson revisited. British Journal of Developmental Psychology, 15(2), 223-236.

Campos, J. J., Anderson, D. I., Barbu-Roth, M. A., Hubbard, E. M., Hertenstein, M. J., \& Witherington, D. (2000). Travel broadens the mind. Infancy, 1(2), 149-219.

Cannon, E. N., Woodward, A. L., Gredebäck, G., von Hofsten, C., \& Turek, C. (2012). Action production influences 12-month-old infants' attention to others' actions. Developmental Science, 15(1), 35-42. https://doi.org/Doi 10.1111/J.1467-7687.2011.01095.X

Caramazza, A., Anzellotti, S., Strnad, L., \& Lingnau, A. (2014). Embodied Cognition and Mirror Neurons: A critical assessment. Annual Review of Neuroscience, 37(1), 1-15. https://doi.org/10.1146/annurev-neuro-071013-013950

Carpenter, M., Akhtar, N., \& Tomasello, M. (1998). Fourteen- through 18-month-old infants differentially imitate intentional and accidental actions. Infant Behavior \& Development, $21(2), 315-330$.

Castiello, U., \& Pierno, A. C. (2009). Reaching and grasping. In L. R. Squire (Hrsg.), Encyclopedia of Neuroscience (S. 23-28). Academic Press. https://doi.org/10.1016/B978008045046-9.01919-7 
Clifton, R. K., Rochat, P., Litovsky, R. Y., \& Perris, E. E. (1991). Object representation guides infants reaching in the dark. Journal of Experimental Psychology-Human Perception and Performance, 17(2), 323-329.

Corbetta, D., \& Thelen, E. (1996). The developmental origins of bimanual coordination: A dynamic perspective. Journal of Experimental Psychology: Human Perception and Performance, 22(2), 502-522. https://doi.org/10.1037/0096-1523.22.2.502

Corbetta, D., Thelen, E., \& Johnson, K. (2000). Motor constraints on the development of perception-action matching in infant reaching. Infant Behavior \& Development, 23, 351374.

Costantini, M., Ambrosini, E., Cardellicchio, P., \& Sinigaglia, C. (2014). How your hand drives my eyes. Social Cognitive and Affective Neuroscience, 9(5), 705-711. https://doi.org/10.1093/scan/nst037

Daum, M. M., \& Gredebäck, G. (2011). The development of grasping comprehension in infancy: Covert shifts of attention caused by referential actions. Experimental Brain Research, 208(2), 297-307. https://doi.org/10.1007/s00221-010-2479-9

Daum, M. M., Huber, S., \& Krist, H. (2007). Controlling reaching movements with predictable and unpredictable target motion in 10-year-old children and adults. Experimental Brain Research, 177(4), 483-492.

Daum, M. M., \& Prinz, W. (2011). Body and action representations for integrating self and other. In V. Slaughter \& C. Brownell (Hrsg.), Early Development of Body Representations (S. 267-282). Cambridge University Press.

Daum, M. M., Prinz, W., \& Aschersleben, G. (2008). Encoding the goal of an object-directed but uncompleted reaching action in 6- and 9-month-old infants. Developmental Science, 
11(4), 607-619. https://doi.org/10.1111/j.1467-7687.2008.00705.x

Daum, M. M., Prinz, W., \& Aschersleben, G. (2011). Perception and production of object-related grasping in 6-month-olds. Journal of Experimental Child Psychology, 108(4), 810-818.

Delafield-Butt, J. T., Freer, Y., Perkins, J., Skulina, D., Schögler, B., \& Lee, D. N. (2018). Prospective organization of neonatal arm movements: A motor foundation of embodied agency, disrupted in premature birth. Developmental Science, 21(6), e12693. https://doi.org/10.1111/desc.12693

Delafield-Butt, J. T., \& Gangopadhyay, N. (2013). Sensorimotor intentionality: The origins of intentionality in prospective agent action. Developmental Review, 33(4), 399-425. https://doi.org/10.1016/j.dr.2013.09.001

Diamond, A. (2013). Executive Functions. Annual Review of Psychology, 64(1), 135-168. https://doi.org/10.1146/annurev-psych-113011-143750

Domellöf, E., Barbu-Roth, M., Rönnqvist, L., Jacquet, A.-Y., \& Fagard, J. (2015). Infant manual performance during reaching and grasping for objects moving in depth. Frontiers in Psychology, 6. https://doi.org/10.3389/fpsyg.2015.01142

D’Souza, H., Cowie, D., Karmiloff-Smith, A., \& Bremner, A. J. (2017). Specialization of the motor system in infancy: From broad tuning to selectively specialized purposeful actions. Developmental Science, 20(4), e12409. https://doi.org/10.1111/desc.12409

Elsner, C., Bakker, M., Rohlfing, K., \& Gredebäck, G. (2014). Infants’ online perception of giveand-take interactions. Journal of Experimental Child Psychology, 126, 280-294. https://doi.org/10.1016/j.jecp.2014.05.007

Elsner, C., D’Ausilio, A., Gredebäck, G., Falck-Ytter, T., \& Fadiga, L. (2013). The motor cortex is causally related to predictive eye movements during action observation. 
Neuropsychologia, 51(3), 488-492.

Falck-Ytter, T., Gredebäck, G., \& von Hofsten, C. (2006). Infants predict other people’s action goals. Nature Neuroscience, 9(7), 878-879. https://doi.org/10.1038/nn1729

Farroni, T., Csibra, G., Simion, F., \& Johnson, M. H. (2002). Eye contact detection in humans from birth. Proceedings of the National Academy of Sciences, 99(14), 9602-9605.

Feigenson, L., Dehaene, S., \& Spelke, E. (2004). Core systems of number. Trends in Cognitive Sciences, 8(7), 307-314. https://doi.org/10.1016/j.tics.2004.05.002

Forssberg, H., Kinoshita, H., Eliasson, A. C., Johansson, R. S., Westling, G., \& Gordon, A. M. (1992). Development of human precision grip II. Anticipatory control of isometric forces targeted for object's weight. Experimental Brain Research, 90(2), 393-398. https://doi.org/10.1007/BF00227253

Frick, A., \& Möhring, W. (2013). Mental object rotation and motor development in 8- and 10month-old infants. Journal of Experimental Child Psychology, 115(4), 708-720. https://doi.org/10.1016/j.jecp.2013.04.001

Friederici, A. D. (2004). Event-related brain potential studies in language. Current Neurology and Neuroscience Reports, 4(6), 466-470. https://doi.org/10.1007/s11910-004-0070-0

Friederici, A. D. (2005). Neurophysiological markers of early language acquisition: From syllables to sentences. Trends in Cognitive Sciences, 9(10), 481-488. https://doi.org/DOI 10.1016/j.tics.2005.08.008

Friedrich, M., \& Friederici, A. D. (2005). Phonotactic knowledge and lexical-semantic processing in one-year-olds: Brain responses to words and nonsense words in picture contexts. Journal of Cognitive Neuroscience, 17(11), 1785-1802.

https://doi.org/10.1162/089892905774589172 
Fuchs, T. (2017). Ecology of the Brain. The phenomenology and biology of the embodied mind. https://doi.org/10.1093/med/9780199646883.001.0001

Gampe, A., Brauer, J., \& Daum, M. M. (2016). Imitation is beneficial for verb learning in toddlers. European Journal of Developmental Psychology, 13(5), 594-613. https://doi.org/10.1080/17405629.2016.1139495

Gampe, A., \& Daum, M. M. (2014). Productive verbs facilitate action prediction in toddlers. Infancy, 19(3), 301-325. https://doi.org/10.1111/infa.12047

Gatti, R., Rocca, M. A., Fumagalli, S., Cattrysse, E., Kerckhofs, E., Falini, A., \& Filippi, M. (2017). The effect of action observation/execution on mirror neuron system recruitment: An fMRI study in healthy individuals. Brain Imaging and Behavior, 11(2), 565-576. https://doi.org/10.1007/s11682-016-9536-3

Ger, E., Altınok, N., Liszkowski, U., \& Küntay, A. C. (2018). Development of infant pointing from 10 to 12 months: The role of relevant caregiver responsiveness. Infancy, 23(5), 708729. https://doi.org/10.1111/infa.12239

Ger, E., Wermelinger, S., de Ven, M., \& Daum, M. M. (2021). What's the point?: Infants' and adults' perception of different pointing gestures. Manuscript in preparation for submission.

Ghirlanda, S., Lind, J., \& Enquist, M. (2017). Memory for stimulus sequences: A divide between humans and other animals? Royal Society Open Science, 4(6), 161011. https://doi.org/10.1098/rsos.161011

Gibson, E. J. (1978). C'est Moi. Contemporary Psychology, 23(9), 609-611. https://doi.org/10.1037/017465

Gottwald, J. M. (2018). Measuring prospective motor control in action development. Journal of 
Motor Learning and Development, 6(s1), S126-S137. https://doi.org/10.1123/jmld.20160078

Gottwald, J. M., Achermann, S., Marciszko, C., Lindskog, M., \& Gredebäck, G. (2016). An embodied account of early executive-function development: Prospective motor control in infancy Is related to inhibition and working memory. Psychological Science, 27(12), 1600-1610. https://doi.org/10.1177/0956797616667447

Gottwald, J. M., De Bortoli Vizioli, A., Lindskog, M., Nyström, P., Ekberg, T. L., von Hofsten, C., \& Gredebäck, G. (2017). Infants prospectively control reaching based on the difficulty of future actions: To what extent can infants' multiple-step actions be explained by Fitts' law? Developmental Psychology, 53(1), 4-12.

https://doi.org/10.1037/dev0000212

Gottwald, J. M., \& Gredebäck, G. (2015). Infants’ prospective control during object manipulation in an uncertain environment. Experimental Brain Research, 233(8), 23832390. https://doi.org/10.1007/s00221-015-4308-7

Granrud, C. E., Yonas, A., Smith, I. M., Arterberry, M. E., Glicksman, M. L., \& Sorknes, A. C. (1984). Infants' sensitivity to accretion and deletion of texture as information for depth at an edge. Child Development, 55(4), 1630. https://doi.org/10.2307/1130032

Gredebäck, G. (2018). How visual and motor experience shapes the development of infants’ perception of actions performed by social partners. Journal of Motor Learning and Development, 6(s1), S89-S104. https://doi.org/10.1123/jmld.2016-0074

Gredebäck, G., \& Daum, M. M. (2015). The microstructure of action perception in infancy: Decomposing the temporal structure of social information processing. Child Development Perspectives, 9(2), 79-83. https://doi.org/10.1111/cdep.12109 
Gredebäck, G., \& Falck-Ytter, T. (2015). Eye movements during action observation.

Perspectives in Cognitive Science, 10(5), 591-598.

https://doi.org/10.1177/1745691615589103

Gredebäck, G., \& Kochukhova, O. (2010). Goal anticipation during action observation is influenced by synonymous action capabilities, a puzzling developmental study. Experimental Brain Research, 202(2), 493-497. https://doi.org/DOI 10.1007/s00221009-2138-1

Gredebäck, G., Lindskog, M., Juvrud, J. C., Green, D., \& Marciszko, C. (2018). Action prediction allows hypothesis testing via internal forward models at 6 months of age. Frontiers in Psychology, 9. https://doi.org/10.3389/fpsyg.2018.00290

Gredebäck, G., \& Melinder, A. M. D. (2010). Infants' understanding of everyday social interactions: A dual process account. Cognition, 114(2), 197-206. https://doi.org/10.1016/j.cognition.2009.09.004

Gredebäck, G., Melinder, A. M. D., \& Daum, M. M. (2010). The neural basis and development of pointing comprehension. Social Neuroscience, 5(5-6), 441-450. https://doi.org/10.1080/17470910903523327

Gredebäck, G., Örnkloo, H., \& von Hofsten, C. (2006). The development of reactive saccade latencies. Experimental Brain Research, 173(1), 159-164. https://doi.org/10.1007/s00221-006-0376-z

Gredebäck, G., Stasiewicz, D., Falck-Ytter, T., von Hofsten, C., \& Rosander, K. (2009). Action type and goal type modulate goal-directed gaze shifts in 14-month-old infants. Developmental Psychology, 45(4), 1190-1194. https://doi.org/10.1037/a0015667 Halberda, J., \& Feigenson, L. (2008). Developmental change in the acuity of the „number 
sense“: The approximate number system in 3-, 4-, 5-, and 6-year-olds and adults. Developmental Psychology, 44(5), 1457-1465. https://doi.org/10.1037/a0012682

Hespos, S. J., Gredebäck, G., von Hofsten, C., \& Spelke, E. S. (2009). Occlusion is hard: Comparing predictable reaching for visible and hidden objects in infants and adults. Cognitive Science, 33, 1483-1502.

Hoch, J. E., O'Grady, S. M., \& Adolph, K. E. (2019). It's the journey, not the destination: Locomotor exploration in infants. Developmental Science, 22(2), e12740. https://doi.org/10.1111/desc. 12740

Hrvoj-Mihic, B., Bienvenu, T., Stefanacci, L., Muotri, A. R., \& Semendeferi, K. (2013). Evolution, development, and plasticity of the human brain: From molecules to bones. Frontiers in Human Neuroscience, 7. https://doi.org/10.3389/fnhum.2013.00707

Ito, M. (2008). Control of mental activities by internal models in the cerebellum. Nature Reviews Neuroscience, 9(4), 304-313. https://doi.org/10.1038/nrn2332

Iverson, J. M., \& Goldin-Meadow, S. (2005). Gesture paves the way for language development. Psychological Science, 16(5), 367-371. https://doi.org/10.1111/j.09567976.2005.01542.x

Izard, V., Sann, C., Spelke, E. S., \& Streri, A. (2009). Newborn infants perceive abstract numbers. Proceedings of the National Academy of Sciences, 106(25), 10382-10385. https://doi.org/10.1073/pnas.0812142106

Jackson, I., \& Sirois, S. (2009). Infant cognition: Going full factorial with pupil dilation. Developmental Science, 12(4), 670-679.

Jeannerod, M. (1981). Intersegmental coordination during reaching at natural visual objects. In J. Long \& A. Baddeley (Hrsg.), Attention and performance IX (S. 153-168). Erlbaum. 
Johnson, M. H. (2011). Interactive specialization: A domain-general framework for human functional brain development? Developmental Cognitive Neuroscience, 1(1), 7-21. https://doi.org/10.1016/j.den.2010.07.003

Johnson, M. H., Dziurawiec, S., Ellis, H., \& Morton, J. (1991). Newborns’ preferential tracking of face-like stimuli and its subsequent decline. Cognition, 40(1-2), 1-19.

Johnson, S. P. (2010). How infants learn about the visual world. Cognitive Science, 34(7), 11581184. https://doi.org/10.1111/j.1551-6709.2010.01127.x

Juvrud, J. C., Bakker, M., Kaduk, K., DeValk, J. M., Gredebäck, G., \& Kenward, B. (2019). Longitudinal continuity in understanding and production of giving-related behavior from infancy to childhood. Child Development, 90(2), e182-e191. https://doi.org/10.1111/cdev.13131

Karmiloff-Smith, A. (2015). An alternative to domain-general or domain-specific frameworks for theorizing about human evolution and ontogenesis. AIMS Neuroscience, 2(2), 91-104. https://doi.org/10.3934/Neuroscience.2015.2.91

Karr, J. E., Areshenkoff, C. N., Rast, P., Hofer, S. M., Iverson, G. L., \& Garcia-Barrera, M. A. (2018). The unity and diversity of executive functions: A systematic review and reanalysis of latent variable studies. Psychological Bulletin, 144(11), 1147-1185. https://doi.org/10.1037/bu10000160

Kenward, B., Koch, F.-S., Forssman, L., Brehm, J., Tidemann, I., Sundqvist, A., Marciszko, C., Hermansen, T. K., Heimann, M., \& Gredebäck, G. (2017). Saccadic reaction times in infants and adults: Spatiotemporal factors, gender, and interlaboratory variation. Developmental Psychology, 53(9), 1750-1764. https://doi.org/10.1037/dev0000338

Kilner, J. M., Friston, K. J., \& Frith, C. D. (2007). Predictive coding: An account of the mirror 
neuron system. Cognitive processing, 8(3), 159-166.

Kita, S. (2003). Pointing: Where language, culture, and cognition meet. Psychology Press.

Lakoff, G., \& Núñez, R. (2000). Where mathematics comes from (Bd. 6). New York: Basic Books.

Leung, E. H., \& Rheingold, H. L. (1981). Development of pointing as a social gesture. Developmental Psychology, 17(2), 215-220.

Lindskog, M., Schröder, E., Kenward, B., \& Gredebäck, G. (Manuscript under review). Play and the development of numerical abilities.

Lingnau, A., \& Caramazza, A. (2014). The origin and function of mirror neurons: The missing link. Behavioral and Brain Sciences, 37(02), 209-210. https://doi.org/10.1017/S0140525X13002380

Liszkowski, U., Brown, P., Callaghan, T., Takada, A., \& Vos, C. de. (2012). A prelinguistic gestural universal of human communication. Cognitive Science, 36(4), 698-713. https://doi.org/10.1111/j.1551-6709.2011.01228.x

Liszkowski, U., Carpenter, M., Henning, A., Striano, T., \& Tomasello, M. (2004). Twelvemonth-olds point to share attention and interest. Developmental Science, 7(3), 297-307.

Liszkowski, U., \& Tomasello, M. (2011). Individual differences in social, cognitive, and morphological aspects of infant pointing. Cognitive Development, 26(1), 16-29. https://doi.org/10.1016/j.cogdev.2010.10.001

Lock, A., Young, A., Service, V., \& Chandler, P. (1990). Some observations on the origins of the pointing gesture. In V. Volterra \& C. J. Erting (Hrsg.), From Gesture to Language in Hearing and Deaf Children (S. 42-55). Springer. https://doi.org/10.1007/978-3-64274859-2_5 
Lockman, J. J., Ashmead, D. H., \& Bushnell, E. W. (1984). The development of anticipatory hand orientation during infancy. Journal of Experimental Child Psychology, 37, 176-186.

Loucks, J., \& Sommerville, J. A. (2012). The role of motor experience in understanding action function: The case of the precision grasp. Child Development. https://doi.org/10.1111/j.1467-8624.2012.01735.x

Lüke, C., Grimminger, A., Rohlfing, K. J., Liszkowski, U., \& Ritterfeld, U. (2017). In infants’ hands: Identification of preverbal infants at risk for primary language delay. Child Development, 88(2), 484-492. http://onlinelibrary.wiley.com/doi/10.1111/cdev.12610/abstract. https://doi.org/10.1111/cdev.12610

Maffongelli, L., Antognini, K., \& Daum, M. M. (2018). Syntactical regularities of action sequences in the infant brain: When structure matters. Developmental Science, 21(6), e12682. https://doi.org/10.1111/desc.12682

Mahon, B. Z. (2015a). What is embodied about cognition? Language, Cognition and Neuroscience, 30(4), 420-429. https://doi.org/10.1080/23273798.2014.987791

Mahon, B. Z. (2015b). The burden of embodied cognition. Canadian Journal of Experimental Psychology = Revue Canadienne De Psychologie Experimentale, 69(2), 172-178. https://doi.org/10.1037/cep0000060

Mani, N., Daum, M. M., \& Huettig, F. (2016). "Proactive" in many ways: Developmental evidence for a dynamic pluralistic approach to prediction. The Quarterly Journal of Experimental Psychology, 69(11), 1-31. https://doi.org/10.1080/17470218.2015.1111395

Mani, N., \& Huettig, F. (2012). Prediction during language processing is a piece of cake-but only for skilled producers. Journal of experimental psychology. Human perception and 
performance, 38(4), 843-847. https://doi.org/10.1037/a0029284

Marciszko, C., Forssman, L., Kenward, B., Lindskog, M., Fransson, M., \& Gredebäck, G. (2020). The social foundation of executive function. Developmental Science, $n / a(\mathrm{n} / \mathrm{a})$, e12924. https://doi.org/10.1111/desc.12924

Melinder, A. M. D., Konijnenberg, C., Hermansen, T., Daum, M. M., \& Gredebäck, G. (2015). The developmental trajectory of pointing perception in the first year of life. Experimental Brain Research, 233, 641-647. https://doi.org/10.1007/s00221-014-4143-2

Melzer, A., Prinz, W., \& Daum, M. M. (2012). Production and observation of contralateral reaching: A close link by 12 months of age. Infant Behavior \& Development, 35(3), 570579. https://doi.org/10.1016/j.infbeh.2012.05.003

Miyake, A., \& Friedman, N. P. (2012). The nature and organization of individual differences in executive functions: Four general conclusions. Current Directions in Psychological Science, 21(1), 8-14. https://doi.org/10.1177/0963721411429458

Molenberghs, P., Cunnington, R., \& Mattingley, J. B. (2012). Brain regions with mirror properties: A meta-analysis of 125 human fMRI studies. Neuroscience \& Biobehavioral Reviews, 36(1), 341-349. https://doi.org/10.1016/j.neubiorev.2011.07.004

Muthukumaraswamy, S. D., \& Johnson, B. W. (2004). Changes in rolandic mu rhythm during observation of a precision grip. Psychophysiology, 41, 152-156.

Nelson, K. (1973). Some evidence for the cognitive primacy of categorization and its functional basis. Merrill-Palmer Quarterly of Behavior and Development, 19(1), 21-39.

Newell, K. M., Scully, D. M., McDonald, P. V., \& Baillargeon, R. (1989). Task constraints and infant grip configurations. Developmental Psychobiology, 22(8), 817-831.

Park, D. C., \& Reuter-Lorenz, P. (2009). The adaptive brain: Aging and neurocognitive 
scaffolding. Annual Review of Psychology, 60, 173-196.

https://doi.org/10.1146/annurev.psych.59.103006.093656

Piaget, J. (1953). The origins of intelligence in children. Routledge \& Kegan Paul.

Rakison, D. H., \& Krogh, L. (2011). Does causal action facilitate causal perception in infants younger than 6 months of age? Developmental Science, 15(1), 43-53. https://doi.org/10.1111/j.1467-7687.2011.01096.x

Ramenzoni, V. C., \& Liszkowski, U. (2016). The social reach: 8-month-olds reach for unobtainable objects in the presence of another person. Psychological Science, 27(9), 1278-1285. https://doi.org/10.1177/0956797616659938

Regolin, L., Tommasi, L., \& Vallortigara, G. (2000). Visual perception of biological motion in newly hatched chicks as revealed by an imprinting procedure. Animal Cognition, 3(1), 53-60. https://doi.org/10.1007/s100710050050

Reid, V. M., Hoehl, S., Grigutsch, M., Groendahl, A., Parise, E., \& Striano, T. (2009). The neural correlates of infant and adult goal prediction: Evidence for semantic processing systems. Developmental Psychology, 45(3), 620-629. https://doi.org/10.1037/A0015209

Ridler, K., Veijola, J. M., Tanskanen, P., Miettunen, J., Chitnis, X., Suckling, J., Murray, G. K., Haapea, M., Jones, P. B., Isohanni, M. K., \& Bullmore, E. T. (2006). Fronto-cerebellar systems are associated with infant motor and adult executive functions in healthy adults but not in schizophrenia. Proceedings of the National Academy of Sciences, 103(42), 15651-15656. https://doi.org/10.1073/pnas.0602639103

Rizzolatti, G., \& Fogassi, L. (2014). The mirror mechanism: Recent findings and perspectives. Philosophical Transactions of the Royal Society B: Biological Sciences, 369(1644), 20130420. https://doi.org/10.1098/rstb.2013.0420 
Rodgon, M. M., Jankowski, W., \& Alenskas, L. (1977). A multi-functional approach to singleword usage. Journal of Child Language, 4(1), 23-43. https://doi.org/10.1017/S0305000900000465

Rosander, K., \& von Hofsten, C. (2011). Predictive gaze shifts elicited during observed and performed actions in 10-month-old infants and adults. Neuropsychologia, 49(10), 29112917. https://doi.org/10.1016/j.neuropsychologia.2011.06.018

Schröder, E., Gredebäck, G., Gunnarsson, J., \& Lindskog, M. (2020). Play enhances visual form perception in infancy-an active training study. Developmental Science, n/a(n/a), e12923. https://doi.org/10.1111/desc.12923

Sciutti, A., Lohan, K. S., Gredebäck, G., Koch, B., \& Rohlfing, K. J. (2016). Language meddles with infants' processing of observed actions. Frontiers in Robotics and AI, 3. https://doi.org/10.3389/frobt.2016.00046

Simion, F., Regolin, L., \& Bulf, H. (2008). A predisposition for biological motion in the newborn baby. Proceedings of the National Academy of Sciences of the United States of America, 105(2), 809-813. https://doi.org/10.1073/pnas.0707021105

Slone, L. K., Moore, D. S., \& Johnson, S. P. (2018). Object exploration facilitates 4-month-olds' mental rotation performance. PLOS ONE, 13(8), e0200468. https://doi.org/10.1371/journal.pone.0200468

Smeets, J. B. J., \& Brenner, E. (1999). A new view on grasping. Motor Control, 3(3), 237-271.

Smith, L. B., \& Thelen, E. (2003). Development as a dynamic system. Trends in Cognitive Sciences, 7(8), 343-348. https://doi.org/10.1016/S1364-6613(03)00156-6

Sommerville, J. A., Woodward, A. L., \& Needham, A. (2005). Action experience alters 3-monthold infants' perception of others' actions. Cognition, 96(1), B1-B11. 
Spelke, E. S. (2017). Core knowledge, language, and number. Language Learning and Development, 13(2), 147-170. https://doi.org/10.1080/15475441.2016.1263572

Stahl, A. E., \& Feigenson, L. (2015). Observing the unexpected enhances infants' learning and exploration. Science, 348(6230), 91-94. https://doi.org/10.1126/science.aaa3799

Swingley, D. (2009). Contributions of infant word learning to language development. Philosophical Transactions of the Royal Society B: Biological Sciences, 364(1536), 3617-3632. https://doi.org/10.1098/rstb.2009.0107

Thelen, E. (1979). Rhythmical stereotypies in normal human infants. Animal Behaviour, 27, 699-715. https://doi.org/10.1016/0003-3472(79)90006-X

Thelen, E. (1992). Development as a Dynamic System. Current Directions in Psychological Science, 1(6), 189-193. https://doi.org/10.1111/1467-8721.ep10770402

Thelen, E., \& Corbetta, D. (2002). Microdevelopment and dynamic systems: Applications to infant motor development. Microdevelopment: Transition processes in development and learning, 59-79.

Thelen, E., Corbetta, D., Kamm, K., Spencer, J. P., Schneider, K., \& Zernicke, R. F. (1993). The transition to reaching: Mapping intention and intrinsic dynamics. Child Development, 64(4), 1058-1098. https://doi.org/10.1111/j.1467-8624.1993.tb04188.x

Thelen, E., Corbetta, D., \& Spencer, J. P. (1996). Development of reaching during the first year: Role of movement speed. Journal of Experimental Psychology: Human Perception and Performance, 22(5), 1059-1076. https://doi.org/10.1037/0096-1523.22.5.1059

Tomasello, M., \& Farrar, M. J. (1986). Joint attention and early language. Child Development, 57(6), 1454-1463. https://doi.org/10.2307/1130423

van der Meer, A. L. H., van der Weel, F. R., \& Lee, D. N. (1995). The functional significance of 
arm movements in neonates. Science, 267, 693-695.

von Hofsten, C. (1983). Catching skills in infancy. Journal of Experimental Psychology: Human Perception and Performance, 9(1), 75-85. https://doi.org/10.1037/0096-1523.9.1.75

von Hofsten, C. (1984). Developmental changes in the organization of prereaching movements. Developmental Psychology, 20(3), 378-388. https://doi.org/10.1037/0012-1649.20.3.378

von Hofsten, C. (2004). An action perspective on motor development. Trends in Cognitive Sciences, 8(6), 266-272.

von Hofsten, C., \& Lindhagen, K. (1979). Observations on the development of reaching for moving objects. Journal of Experimental Child Psychology, 28(1), 158-173. https://doi.org/10.1016/0022-0965(79)90109-7

von Hofsten, C., \& Rönnqvist, L. (1988). Preparation for grasping an object: A developmental study. Journal of Experimental Psychology: Human Perception and Performance, 14(4), 610-621.

Wermelinger, S., Gampe, A., \& Daum, M. M. (2018). The dynamics of the interrelation of perception and action across the life span. Psychological Research, 1-16. https://doi.org/10.1007/s00426-018-1058-8

Wermelinger, S., Gampe, A., \& Daum, M. M. (2019). Higher levels of motor competence are associated with reduced interference in action perception across the lifespan. Psychological Research, 1-13. https://doi.org/10.1007/s00426-017-0941-z

Wilkinson, N., Paikan, A., Gredebäck, G., Rea, F., \& Metta, G. (2014). Staring us in the face? An embodied theory of innate face preference. Developmental science. https://doi.org/10.1111/desc.12159

Williams, J. L., Corbetta, D., \& Cobb, L. (2015). How perception, action, functional value, and 
context can shape the development of infant reaching. Movement \& Sport Sciences Science \& Motricité, 89, 5-15. https://doi.org/10.1051/sm/2015005

Wilson, A. D., \& Golonka, S. (2013). Embodied cognition is not what you think it is. Frontiers in Psychology, 4. https://doi.org/10.3389/fpsyg.2013.00058

Wolpert, D. M., Miall, R. C., \& Kawato, M. (1998). Internal models in the cerebellum. Trends in Cognitive Sciences, 2(9), 338-347. https://doi.org/10.1016/S1364-6613(98)01221-2

Woodward, A. L. (1998). Infants selectively encode the goal object of an actor's reach. Cognition, 69(1), 1-34. https://doi.org/10.1016/S0010-0277(98)00058-4

Zoia, S., Blason, L., D’Ottavio, G., Bulgheroni, M., Pezzetta, E., Scabar, A., \& Castiello, U. (2007). Evidence of early development of action planning in the human foetus: A kinematic study. Experimental Brain Research, 176(2), 217-226. https://doi.org/10.1007/s00221-006-0607-3 